Archived version from NCDOCKS Institutional Repository http://libres.uncg.edu/ir/asu/

\title{
Appalachl̈ăn
}

B O O N E, N O R T H C A R O L I N A

\section{Decelerating The Diminishing Returns Of Citizenship On Task Performance: The Role Of Social Context And Interpersonal Skill}

\author{
By: J. Kemp Ellington, Erich C. Dierdorff, and Robert S. Rubin
}

\begin{abstract}
Recent scholarship on citizenship behavior demonstrates that engaging too often in these behaviors comes at the expense of task performance. In order to examine the boundary conditions of this relationship, we used resource allocation and social exchange theories to build predictions regarding moderators of the curvilinear association between citizenship and task performance. We conducted a field study of 366 employees, in which we examined the relationship between the frequency of interpersonal helping behavior and task performance and tested for the moderating influences of 3 social context features (social density, interdependence, and social support) and of employees' levels of interpersonal skill. Results provided corroborating evidence of the diminishing returns between citizenship and task performance. Further, these diminishing returns were decelerated when contexts were characterized by high interdependence and social density and when employees possessed strong interpersonal skills. Implications for extending future citizenship theory and research to incorporate curvilinearity are presented.
\end{abstract}

Ellington, J. K., Dierdorff, E. C., \& Rubin, R. S. (2014). Decelerating the diminishing returns of citizenship on task performance: The role of social context and interpersonal skill. Journal of Applied Psychology, 99(4), 748-758. http://dx.doi.org/10.1037/a0036102. Publisher version of record available at: http://psycnet.apa.org/record/2014-08118-001 


\title{
Decelerating the Diminishing Returns of Citizenship on Task Performance: The Role of Social Context and Interpersonal Skill
}

\author{
J. Kemp Ellington \\ Illinois Institute of Technology
}

\author{
Erich C. Dierdorff and Robert S. Rubin \\ DePaul University
}

\begin{abstract}
Recent scholarship on citizenship behavior demonstrates that engaging too often in these behaviors comes at the expense of task performance. In order to examine the boundary conditions of this relationship, we used resource allocation and social exchange theories to build predictions regarding moderators of the curvilinear association between citizenship and task performance. We conducted a field study of 366 employees, in which we examined the relationship between the frequency of interpersonal helping behavior and task performance and tested for the moderating influences of 3 social context features (social density, interdependence, and social support) and of employees' levels of interpersonal skill. Results provided corroborating evidence of the diminishing returns between citizenship and task performance. Further, these diminishing returns were decelerated when contexts were characterized by high interdependence and social density and when employees possessed strong interpersonal skills. Implications for extending future citizenship theory and research to incorporate curvilinearity are presented.
\end{abstract}

Keywords: organizational citizenship behavior, contextual performance, task performance, social context, interpersonal skill

Scholars have long recognized that work roles require behaviors that are task focused as well as those that are social, cooperative, and helpful in nature (Katz \& Kahn, 1978). Research supports this assertion, with evidence demonstrating job performance consists of both task and citizenship behaviors (Hoffman, Blair, Meriac, \& Woehr, 2007; Van Scotter, Motowidlo, \& Cross, 2000; Viswesvaran \& Ones, 2000). Empirical evidence also shows that citizenship benefits not only individuals performing the behavior (e.g., increased performance evaluations) but organizations as well (e.g., productivity, efficiency, reduced costs, customer satisfaction, and reduced turnover; Podsakoff, Whiting, Podsakoff, \& Blume, 2009). In light of such convincing evidence, one might assume that "more is always better" as it pertains to citizenship behaviors.

Yet, recent scholarship has begun to question whether the relationship between citizenship and task performance is consistently positive. For example, engaging in citizenship, as well as feelings of pressure to perform such behaviors, has been linked to negative outcomes such as job stress, role overload, and work-family

J. Kemp Ellington, Department of Psychology, Lewis College of Human Sciences, Illinois Institute of Technology; Erich C. Dierdorff and Robert S. Rubin, Department of Management, Kellstadt Graduate School of Business, DePaul University.

Correspondence concerning this article should be addressed to J. Kemp Ellington, Department of Psychology, Lewis College of Human Sciences, Illinois Institute of Technology, 3105 South Dearborn Street, Chicago, IL 60616. E-mail: jellingt@iit.edu conflict (Bolino \& Turnley, 2005; Bolino, Turnley, Gilstrap, \& Suazo, 2010; Halbesleben, Harvey, \& Bolino, 2009; VigodaGadot, 2006). Scholars have also suggested that citizenship may undermine task performance under certain circumstances, with some employees engaging in citizenship at the expense of their in-role duties, perhaps ignoring in-role tasks they dislike (Bolino, Turnley, \& Niehoff, 2004). Hanson and Borman (2006) noted that excessive citizenship could inhibit task performance, explaining that the relationship "could be curvilinear, dropping off at higher levels” (p. 169). Finally, drawing on Becker (1965), Bergeron (2007) argued from a resource allocation theory perspective that spending time on activities such as citizenship behavior comes at the expense of time spent on core tasks, creating a "paradox" for employees where performing citizenship may diminish task performance and other outcomes such as raises or promotions.

Indeed, emerging research has begun to find more specific support for the performance trade-offs associated with citizenship behavior. Bergeron, Shipp, Rosen, and Furst (2013) found that, controlling for time spent on task performance, employees who devoted more time to citizenship had lower salary increases and advanced more slowly than those who spent less time on it. In a sample of job incumbents from a wide variety of occupations, Rubin, Dierdorff, and Bachrach (2013) found a curvilinear relationship between the frequency with which citizenship was performed and supervisor-rated task performance. Similarly, Rapp, Bachrach, and Rapp (2013) found curvilinearity between helping behavior and objective task outcomes among sales personnel (call activity and quota percentage). Such evidence suggests that the citizenship-task performance relationship is more complex than previously assumed, often showing initially positive benefits that 
reach an inflection point as personal investments in citizenship increase.

Although recent findings portray the diminishing returns of engaging in too much citizenship, pertinent questions remain. Given that citizenship behavior such as interpersonal helping revolves around social contributions that form the basis for reciprocal exchanges, one question pertains to how the social context of work might affect the demonstrated curvilinearity between citizenship and task performance. The social context includes interpersonal characteristics of the work environment, such as social density, interdependence, and social support (Dierdorff, Rubin, \& Morgeson, 2009; Johns, 2006). Because these particular aspects of work context are known to "shape interpersonal exchanges and interactions” (Dierdorff et al., 2009, p. 976), it stands to reason that the social context impinges upon the frequency and importance of citizenship behavior and thus influences the point of diminishing returns demonstrated in previous studies. In addition, as employees navigate the social context of work, the effective deployment of citizenship behavior rests squarely on their own personal capabilities to facilitate effective interpersonal exchanges. These interpersonal skills are goal-directed behaviors, which primarily include relationshipbuilding competencies (Klein, DeRouin, \& Salas, 2006). Those who are more adept at navigating and facilitating interpersonal interactions with coworkers may be more efficient in their allocation of resources to the social aspects of their work roles, which could impact the diminishing returns of citizenship on task performance.

With the preceding discussion in mind, the goals in the current study are twofold. First, we extend the emerging research on the curvilinearity between citizenship and task performance by examining social context moderators. Second, we extend prior citizenship research in general by incorporating interpersonal skill and examining its potential moderating role in the citizenship-task performance relationship. We draw on elements of resourceallocation theory (Becker, 1965), social exchange theory (Blau, 1964), and organizational role theory (Katz \& Kahn, 1978) to develop moderation hypotheses for these contextual and skill differences. Our study contributes to the extant literature by establishing boundary conditions for the curvilinear effects found in previous studies as well as identifying factors that may operate to intensify or alleviate the diminishing returns of citizenship in the form of interpersonal helping behavior.

\section{The Moderating Role of Social Context}

Context is broadly defined as "situational opportunities and constraints that affect the occurrence and meaning of organizational behavior as well as functional relationships between variables" (Johns, 2006, p. 386). Distinct dimensions of context include the task, social, and physical contexts (Hattrup \& Jackson, 1996; Johns, 2006; Morgeson \& Dierdorff, 2010; Mowday \& Sutton, 1993), each of which can exert a direct or moderating influence on behavior. Given the social nature of organizational citizenship, characteristics of the social context are likely to be particularly influential in moderating the association with task performance.

Citizenship performance is believed to be a form of social exchange (Blau, 1964; Organ, Podsakoff, \& MacKenzie, 2006), and the social context of work is especially salient in determining the type, importance, and frequency of interpersonal exchanges and interactions in the workplace (Dierdorff et al., 2009; Morgeson \& Dierdorff, 2010). Furthermore, elements of social context have been shown to moderate the degree to which employees' prosocial role expectations translate into actual performance of citizenship behaviors (Dierdorff, Rubin, \& Bachrach, 2012). ${ }^{1}$ That is, employees interact with coworkers more frequently in certain types of work contexts and thus are provided increased opportunities to engage in citizenship as a part of their work roles. Characteristics of the social context may act to heighten social demands on employees and can create environments in which citizenship is more likely to have a facilitative relationship with task performance (even at higher levels of citizenship). Therefore, we contend that social context moderates relationships between citizenship and task performance. In this study, we examined three elements of social context: social density, interdependence, and social support (Johns, 2006; Morgeson \& Dierdorff, 2010).

\section{Social Density}

Social density refers to the total number of individuals in a particular work context (Paulus, 1980). In social contexts characterized by a high level of social density, there is an increased potential for interpersonal interactions during work (Fried, Slowik, Ben-David, \& Tiegs, 2001). For example, previous research has indicated a positive association between social density and interpersonal information exchanges (Szilagyi \& Holland, 1980). In this case, the mere presence of others creates increased opportunities for work-related social exchanges. Working closely and frequently interacting with others should increase chances for establishing reciprocal exchanges and norms of reciprocity that seed future reciprocated helping behaviors (Blau, 1964; Organ et al., 2006). The level of social density in the social context should therefore serve as a moderator of the citizenship-task performance relationship. The facilitative effect of citizenship on task performance should be prolonged even at higher frequencies of helping behavior due to the increased interactions that are likely to be supportive of an individual's task performance, thereby delaying the inflection point at which citizenship becomes "too much of a good thing." Therefore, we expect that socially dense work contexts will act to attenuate the diminishing returns of citizenship frequency on task performance.

Hypothesis 1: Socially dense contexts will attenuate the diminishing returns of citizenship frequency on task performance.

\section{Interdependence}

Interdependence characterizes the connectedness among work roles (Morgeson \& Humphrey, 2006) and indicates the extent to which task performance requires reciprocal interactions with others (Dierdorff \& Morgeson, 2007). In occupations with highly interdependent work roles, workload sharing, information sharing, and boundary spanning activities are critical for performance (Katz-Navon \& Erez, 2005; Kiggundu, 1981; Kozlowski, Gully,

\footnotetext{
${ }^{1}$ By "prosocial" role expectations we simply mean behavior that is directed toward individuals or the organization and for the welfare or benefit of others (Brief \& Motowidlo, 1986) and do not suggest a particula motivation for engaging in such behavior (e.g., Grant \& Mayer, 2009).
} 
Nason, \& Smith, 1999; McIntyre \& Salas, 1995). Organ et al. (2006) argued that interdependent contexts "foster social norms of cooperation and increase the need for collective social responsibility" (p. 120). Research supports this assertion by showing citizenship behaviors are more important to individual and group performance in more interdependent environments (Bachrach, Powell, Bendoly, \& Richey, 2006; Bachrach, Wang, Bendoly, \& Zhang, 2007).

Thus, under conditions of high interdependence where substantial social interaction is required, individuals are more likely to engage in citizenship such as helping others than they are in less interdependent contexts. Yet, in a resource allocation framework, it is likely that the degree of interdependence in the work context affects the emergence of the inflection point between citizenship and task performance. Devoting additional resources toward assisting others in these interdependent contexts is likely to benefit an employee, as he or she is dependent upon others to successfully complete his or her own work tasks. Because conditions of high interdependence promote increased social exchanges and more aptly facilitate individual task performance (Bachrach et al., 2006), such contexts should decelerate the diminishing returns normally associated with increased resource allocations toward citizenship. Interdependence is thus likely to "buffer" the diminishing returns associated with frequently engaging in citizenship.

Hypothesis 2: Interdependent contexts will attenuate the diminishing returns of citizenship frequency on task performance.

\section{Social Support}

Social support reflects the degree to which the social context "provides opportunities for advice and assistance from others" (Morgeson \& Humphrey, 2006, p. 1324). Social exchange theory suggests that when employees receive support and assistance from coworkers and managers, norms of reciprocity engender feelings of obligation, compelling individuals to repay those who offered support (Blau, 1964; Organ et al., 2006). Furthermore, the more assistance an employee receives from coworkers, the more likely the individual is to reciprocate. Such reciprocation can manifest in the form of citizenship behavior (Deckop, Cirke, \& Andersson, 2003). Research also indicates that employees are prone to perceive citizenship behavior as an important part of their roles when they are working in contexts rich in socially supportive exchanges (Dierdorff et al., 2012).

The extent to which a work context is socially supportive is also likely to make resource allocation decisions more complex with respect to performing citizenship. In work contexts with little social support, employees will likely find it more difficult to establish reciprocal exchanges of support that benefit their own task performance. In such a case, investing additional resources toward helping coworkers is not likely to result in forms of reciprocity that benefit one's own task performance. Conversely, when the social context provides many opportunities for assistance from others, employees should be able to devote additional resources to prosocial behaviors, thereby deferring the inflection point at which citizenship becomes asymptotic or negative. We therefore expect that socially supportive work contexts will decelerate the diminishing returns of citizenship frequency on task performance.
Hypothesis 3: Socially supportive contexts will attenuate the diminishing returns of citizenship frequency on task performance.

\section{The Moderating Role of Interpersonal Skill}

Given the importance of the social context and socially oriented nature of citizenship behavior, employees with higher levels of skill in establishing and maintaining interpersonal interactions may experience a more enduring facilitative effect of citizenship on task performance. Interpersonal skills reflect skills involved in "social sensitivity, relationship building, working with others, listening, and communication” (Lievens \& Sackett, 2012, p. 460).

Such skills are known to be related to job performance, as well as to evaluations of future potential, promotion, and career success (Gaugler, Rosenthal, Thornton, \& Bentson, 1987; Ng, Eby, Sorensen, \& Feldman, 2005). Despite a sizable literature examining interpersonal skills in relation to job performance and career outcomes, little research depicts the role such skills play in regard to citizenship performance. This paucity of research is surprising, given the primary supposition that citizenship is a social process steeped in complex interpersonal exchanges (Organ et al., 2006). If citizenship in fact facilitates social exchanges that ultimately serve to support the task environment, it stands to reason that the quality or effectiveness of these exchanges may be governed in part by the interpersonal capability of the individual engaging in such behavior. Related research suggests that interpersonal skills promote increased cooperation and teamwork necessary to perform a given task (Ferris, Witt, \& Hochwarter, 2001; Morgeson, Reider, \& Campion, 2005). Moreover, the quality of interpersonal interactions has been shown to convey the effects of citizenship on job performance (Ozer, 2011). Put simply, interpersonal skills are likely to bolster the positive effects of citizenship on task performance.

In resource allocation theory, resource limitations constrain a person's capacity to direct attention to multiple job requirements (Kahneman, 1973). Because interpersonally skilled individuals are likely more effective in social interactions that underlie citizenship behavior, they may be able to invest fewer resources in citizenship and still effectively establish reciprocal exchanges that benefit their own task performance. Further, interpersonal skill involves heightened sensitivity to others (Ferris et al., 2001; Riggio, 1986); interpersonally skilled individuals may thus be more strategic in their allocation of citizenship, reserving engagement in citizenship to situations that are most likely to facilitate task performance. That is, increased investments in citizenship by interpersonally skilled employees likely buffer task performance trade-offs, thereby prolonging the positive effects of citizenship.

Hypothesis 4: High interpersonal skill will attenuate the diminishing returns of citizenship frequency on task performance.

\section{Method}

\section{Participants, Procedure, and Measures}

Participants were 366 individuals who were employed full time and enrolled part time in a graduate school of business at a large private midwestern university. Average age was 32.12 years; 58\% were male. The average tenure of participants in their current jobs 
was 5.88 years $(S D=1.75)$, and the average tenure in their current organizations was 6.27 years $(S D=1.34)$.

Measures were collected on two surveys. The exception was interpersonal skill, which was collected during a developmental assessment center 3 months prior (on average). The first survey collected participants' ratings of citizenship frequency, social density, interdependence, and social support. Demographic information was also collected. Two versions of this first survey were created, with items counterbalanced in order to minimize potential order effects, and participants were randomly assigned to a version of the survey. Roughly five weeks later, a second survey measured participants' levels of task performance. These data were collected from the participants' immediate supervisors and were compiled as developmental feedback along with other performance-related ratings (e.g., leadership, administration, ethics).

Participants also completed the Iliad Assessment Center (Bommer \& Bartels, 1996), an academic assessment center designed to provide developmental feedback. Assessment centers such as Iliad have been used frequently in research to assess various forms of interpersonal skill (see Arthur, Day, McNelly, \& Edens, 2003; Hoover, Giamhatista, Sorenson, \& Bommer, 2010; Rode et al., 2005). The assessment center included two 20-min leaderless group discussions ("non-assigned role"; Thornton \& MuellerHanson, 2004) in which interpersonal skill behaviors were elicited and observed. Six participants were randomly assigned to each group discussion. Separate pairs of independent assessors (master'sand doctoral-level industrial/organizational psychology students, blind to this study's intent) viewed video recordings and evaluated each participant's behavior. Assessors completed an extensive 2day workshop designed to establish a common frame of reference for the respective ratings (Bernardin \& Buckley, 1981).

Citizenship performance. The frequency with which participants engaged in citizenship was measured with the five-item "interpersonal helping" subscale described by Moorman and Blakely (1995). This scale focuses on the extent that individuals help coworkers when such help is needed. Important to our focus is that interpersonal helping has been put forth as a citizenship dimension that is highly consumptive of resources (Nielsen, Bachrach, Sundstrom, \& Halfhill, 2012; Rapp et al., 2013). Participants rated the frequency with which they engaged in interpersonal helping as part of their jobs. Items began with the prompt "How often do you do each behavior as part of performing your job?" and were rated with a job analytic frequency scale with values of 1 (never), 2 (rarely), 3 (sometimes), 4 (often), and 5 (very often; Morgeson \& Dierdorff, 2010). Sample items include "go out of your way to help coworkers with work-related problems," "help new employees settle into the job," and "adjust your schedule to accommodate other employees' requests for time off."

Task performance. This variable was assessed with five items rated on a five-point scale created for this study $(1=$ definitely not descriptive, 2 = not descriptive, 3 = somewhat descriptive, 4 = descriptive, 5 = very descriptive). Each participant's immediate supervisor was asked if the person "gets the job's tasks done," "demonstrates effectiveness in accomplishing major work goals," "strives for quality in his/her tasks," "handles multiple task demands and priorities effectively," and "fulfills all technical responsibilities required by his/her job."

Social density. Following prior research (e.g., Fried et al., 2001; Oldham \& Fried, 1987; Paulus, 1980), we operationalized social density by asking participants to "estimate the total number of people who work within your immediate physical work location (i.e., your office).” The more people in the location, the higher the social density (Hayduk, 1983). Square-root transformation was applied to these scores to smooth the distribution prior to hypothesis testing.

Interdependence. This social context measure was assessed with the six-item scale developed by Morgeson and Humphrey (2006). Respondents rated items on a five-point scale (1 = strongly disagree, 3 = neutral, 5 = strongly agree). Sample items read "my job requires me to accomplish my job before others complete their job" and "my job depends on the work of many different people for its completion."

Social support. This measure was assessed with the six-item scale developed by Morgeson and Humphrey (2006). Sample items include "my supervisor is concerned about the welfare of the people that work for him/her" and "people I work with take a personal interest in me.” A five-point scale was used (1 = strongly disagree, 3 = neutral, 5 = strongly agree).

Interpersonal skill. This variable was assessed via an assessment center teamwork dimension using a behavioral checklist (Reilly, Henry, \& Smither, 1990) of five behaviors: (a) seeks input from others; (b) checks for common understanding; (c) validates others; (d) does not interrupt others; (e) contributes to the meeting. Although interpersonal skill involves a host of people-related capacities, such teamwork behaviors are foundational to the promotion of cooperation and helping others (Morgeson et al., 2005). Rater pairs used interpretation aids (Lievens, 1998) to determine a consensus score for each item (Sackett \& Wilson, 1982), ranging from 0 (behavior was not performed at all) to 2 (behavior was performed to a great extent) except for "does not interrupt others," which ranged from -1 (performed the behavior) to 0 (did not perform the behavior). Scores were summed to provide each participant a single score.

\section{Analytical Approach}

Hierarchical polynomial regression analyses were used to test hypotheses. All predictors were standardized. Regression models tested for linear and curvilinear effects between citizenship and task performance in two steps, by first entering the citizenship frequency variable and then entering the quadratic term of citizenship frequency. Given a significant and negative quadratic term for citizenship frequency, we then tested the three social context variables and interpersonal skill for moderation (relevant to Hypotheses 1-4). Interaction terms for citizenship frequency and each potential moderator were entered, as were terms for quadratic citizenship frequency and each potential moderator. ${ }^{2}$ As in previous research examining curvilinear effects (e.g., Le et al., 2011; Rubin et al., 2013), moderation was examined by computing inflection points (Weisberg, 2005) associated with each polynomial regression. Moderation is supported by a statistically signif-

\footnotetext{
${ }^{2}$ We collected participants' gender, age, job tenure, and organizational tenure as potential control variables. With the lone exception of the correlation between job tenure and citizenship frequency $(r=.11, p=$ $.04)$, none of these variables showed significant correlations with citizenship frequency, task performance, or the social context variables. We therefore excluded these variables from subsequent analyses.
} 
Table 1

Descriptive Statistics and Correlations for Study Variables

\begin{tabular}{lrrrlllll}
\hline \multicolumn{1}{c}{ Variable } & \multicolumn{1}{c}{$M$} & \multicolumn{1}{c}{$S D$} & 1 & \multicolumn{1}{c}{2} & 3 & 4 & 5 & 6 \\
\hline 1. Citizenship frequency & 3.96 & 0.71 & .89 & & & & \\
2. Social density & 10.56 & 9.84 & $.12^{*}$ &. & & & \\
3. Interdependence & 3.52 & 0.98 & $.11^{*}$ & $.18^{* *}$ & .90 & & \\
4. Social support & 3.79 & 0.85 & .03 & $.22^{* *}$ & $.35^{* *}$ & .91 & & \\
5. Interpersonal skill & 59.10 & 20.90 & $.31^{* *}$ & .09 & .07 & .04 & .82 & \\
6. Task performance & 4.29 & 0.60 & $.18^{* *}$ & $.14^{* *}$ & $.42^{* *}$ & $.24^{* *}$ & $.22^{* *}$ & .94 \\
\hline
\end{tabular}

Note. $N=366$; coefficient alpha estimates shown on the diagonal in italics where applicable. $S D=$ standard deviation.

${ }^{*} p<.05 .{ }^{* *} p<.01$.

icant interaction for either the linear term or the quadratic term, as the inflection point is dependent on both coefficients.

\section{Results}

Table 1 displays means, standard deviations, and correlations for study variables. Results of an initial polynomial regression model supported a curvilinear relationship between citizenship frequency and task performance (see Table 2). Both the linear and quadratic terms were statistically significant (linear $\diamond=.85, S E=$ $.27, p<.001$ and quadratic $=-.71, S E=.31, p<.001$; model $\left.R^{2}=.10, p<.01\right)$, and the quadratic term displayed incremental prediction (!). $\left.R^{2}=.06, p<.01\right)$. With a positive linear term and a negative quadratic term, the pattern of results indicates the positive association between citizenship frequency and task performance diminishes as individuals engage in citizenship with higher frequency (see Figure 1). The point of inflection for these curvilinear effects was .60 SD above the standardized mean of citizenship (inflection point $=-.85 / 2^{*}-.71$ ), replicating recent citizenship-task performance research (Rapp et al., 2013; Rubin et al., 2013).

Hypothesis 1-3 predicted moderating effects of social density, interdependence, and social support such that the diminishing returns of citizenship (i.e., interpersonal helping) frequency on task performance are attenuated or buffered in more socially dense, interdependent, and supportive contexts. Results presented in Tables 3, 4, and 5 demonstrate full support for Hypotheses 1 (social density) and 2 (interdependence) but not for Hypothesis 3 (social support). Finding significant interactions for social density and interdependence, we examined the form of the moderations by replacing the values of social density and interdependence (1 SD

Table 2

Curvilinear Effects of Citizenship Frequency on Task Performance

\begin{tabular}{lccccc}
\hline \multicolumn{1}{c}{ Predictor } & & $S E$ & $t$ & $\left.R^{2}(!) \cdot R^{2}\right)$ & $F$ \\
\hline $\begin{array}{l}\text { Step 1 } \\
\quad \text { Citizenship frequency }\end{array}$ & .11 & .04 & $2.75^{*}$ & $.04^{* *}$ & \\
$\begin{array}{l}\text { Step 2 } \\
\quad \text { Citizenship frequency }\end{array}$ & .85 & .27 & $4.17^{* *}$ & & \\
$\quad \begin{array}{l}\text { Citizenship frequency } \\
\quad \text { (quadratic) }\end{array}$ & -.71 & .31 & $-3.98^{* *}$ & $.10\left(.06^{* *}\right)$ & 12.07 \\
\hline
\end{tabular}

Note. $N=366 . S E=$ standard error.

${ }^{*} p<.05 .{ }^{* *} p<.01$. or $-1 S D$ ) in the model relating citizenship and task performance and by computing the inflection points for each model. Figures 2 and 3 illustrate the relationship differences for contexts high and low in social density and interdependence, respectively. Higher levels of social density and interdependence buffer the diminishing returns of citizenship. Finally, Hypothesis 4 predicted that the diminishing returns of citizenship frequency on task performance are attenuated when individuals possess stronger interpersonal skill. Table 6 provides results for this hypothesis. They show a statistically significant interaction between interpersonal skill and the quadratic term for citizenship frequency, thereby supporting Hypothesis 4. Figure 4 displays this moderation, showing that high interpersonal skill lessens the diminishing returns of citizenship frequency on task performance.

On the basis of an anonymous reviewer's recommendation, we conducted supplemental analyses to examine the contribution of the present study's moderators against those found in prior research. We included accountability and autonomy, which showed significant effects in Rubin et al. (2013). We also included a proxy control for time management, for which Rapp et al. (2013) found significant moderation. This proxy was a variable from the assessment center that measured the extent to which participants exhibited "planning and organizing" behaviors (e.g., prioritization, timely and correct attendance, adherence to time limits). After these three controls were included in the regression analyses, the pattern of results pertinent to our moderation hypotheses remained unchanged in terms of statistical significance and direction (see Table 7).

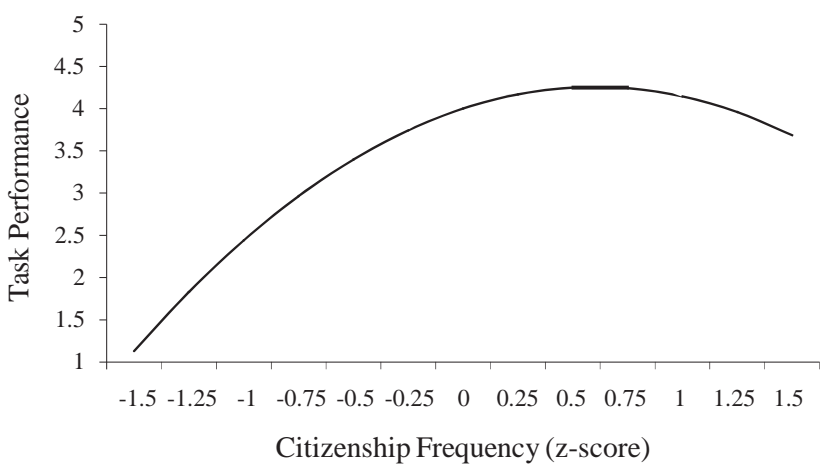

Figure 1. Diminishing returns of citizenship on task performance. 
Table 5

Moderation of Curvilinear Effects by Social Support

\begin{tabular}{|c|c|c|c|c|c|}
\hline Predictor & 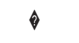 & $S E$ & $T$ & $\left.R^{2}(!) \cdot R^{2}\right)$ & $F$ \\
\hline \multicolumn{6}{|l|}{ Step 1} \\
\hline Citizenship frequency & .85 & .27 & $4.17^{-m}$ & & \\
\hline Citizenship frequency (quadratic) & -.71 & .31 & $-3.98^{* * *}$ & $.10^{* *}$ & \\
\hline \multicolumn{6}{|l|}{ Step 2} \\
\hline Social support & .13 & .03 & $4.15^{* *}$ & & \\
\hline Citizenship frequency & .80 & .22 & $3.52^{* *}$ & & \\
\hline Citizenship frequency (quadratic) & -.76 & .23 & $-3.34^{* *}$ & $.13^{* *}\left(.03^{*}\right)$ & 4.14 \\
\hline \multicolumn{6}{|l|}{ Step 3} \\
\hline Social support & .10 & .04 & $2.80^{* *}$ & & \\
\hline Citizenship frequency & .77 & .22 & $3.39^{* *}$ & & \\
\hline Citizenship frequency (quadratic) & -.71 & .23 & $-3.13^{* *}$ & & \\
\hline Social support $X$ Citizenship frequency & -.10 & .22 & -0.46 & & \\
\hline Social support X Citizenship frequency (quadratic) & .15 & .22 & 0.69 & $.14^{* *}(.01)$ & .83 \\
\hline
\end{tabular}

Note. $N=366$. Dependent variable is task performance. $S E=$ standard error.

${ }^{*} p<.05 .{ }^{* *} p<.01$.

and encourage the establishment of reciprocal exchanges that facilitate task performance (Deckop et al., 2003). Though social support is known to be beneficial to a host of work-related outcomes (Humphrey, Nahrgang, \& Morgeson, 2007), our findings indicate that it does not dampen the resource allocation trade-offs between helping others and task performance.

Though the search for individual difference antecedents has been less than fruitful within the broader citizenship literature (Podsakoff, MacKenzie, Paine, \& Bachrach, 2000), recent research is beginning to uncover the exchange mechanisms that underlie the relationship between citizenship and task performance (e.g., quality of team member exchanges; Ozer, 2011). Yet, primary to the engagement in high-quality exchanges are individuals' capacities to successfully execute such behaviors. That is, some individuals are likely better equipped than others to engage in citizenship that is effective in enhancing performance. Our results confirm that high levels of interpersonal skill extend the benefits of citizenship on task performance. From a resource allocation perspective, interpersonally skilled individuals may receive a higher return on their personal allocation and require less engagement in citizenship

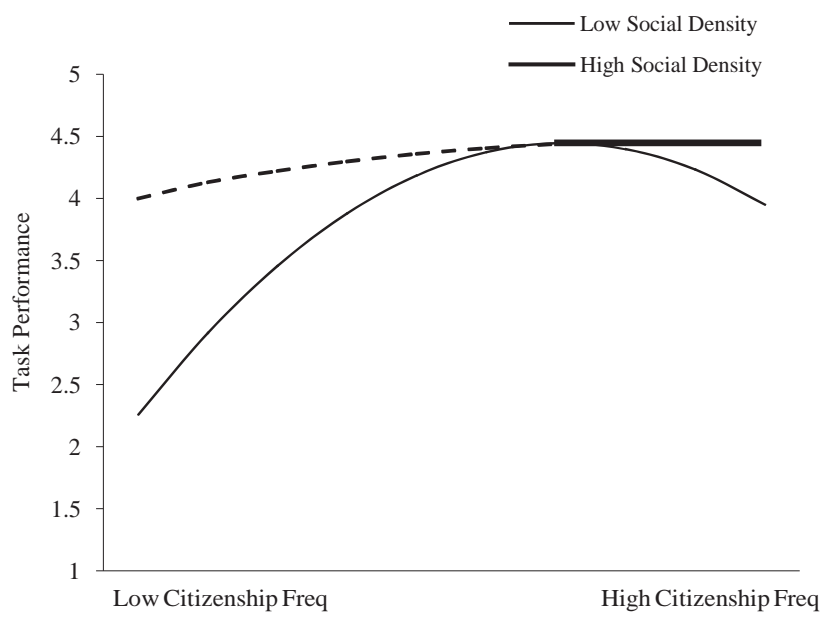

Figure 2. Moderating effects of social density. Freq = frequency . overall than individuals with lower levels of interpersonal skill. It is important to note that we operationalized citizenship as frequency of performance. Thus, although we uncovered the moderating effect of interpersonal skill, the zero-order correlation with citizenship performance was not significant. This finding supports the idea that interpersonal skill does not directly affect whether or not one engages in citizenship but rather shapes the quality of that engagement to benefit task performance.

In conjunction with those of other studies (e.g., Dierdorff et al., 2012), our results again reinforce that "context matters" to citizenship. General patterns also emerge across our study and previous curvilinear findings provided by Rubin et al. (2013) and Rapp et al. (2013). First, irrespective of work context or individual skill, very low levels of citizenship are generally associated with lower levels of task performance. Second, the inflection point of the citizenship-task performance relationship is well within the normal range of behavior, again regardless of the contextual or individual difference variable studied. It is clear that "too much" citizenship is not much beyond the typical occurrence of the behavior. Third, task and social contexts appear to weaken the diminishing returns, yet the degree of buffering appears to vary.

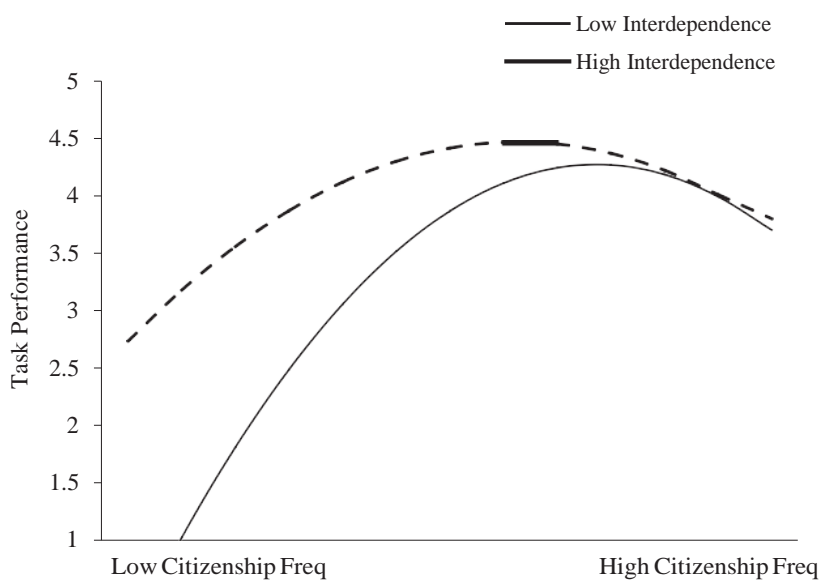

Figure 3. Moderating effects of interdependence. Freq = frequency. 
Table 6

Moderation of Curvilinear Effects by Interpersonal Skill

\begin{tabular}{|c|c|c|c|c|c|}
\hline Predictor & 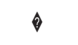 & $S E$ & $t$ & $\left.R^{2}(!) \cdot R^{2}\right)$ & $F$ \\
\hline \multicolumn{6}{|l|}{ Step 1} \\
\hline Citizenship frequency & .85 & .27 & $4.17^{-1}$ & & \\
\hline Citizenship frequency (quadratic) & -.71 & .31 & $-3.98^{* *}$ & $.10^{* *}$ & \\
\hline \multicolumn{6}{|l|}{ Step 2} \\
\hline Interpersonal skill & .18 & .05 & $3.64^{* *}$ & & \\
\hline Citizenship frequency & .52 & .24 & $2.02^{*}$ & & \\
\hline Citizenship frequency (quadratic) & -.51 & .24 & $-1.98^{*}$ & $.13^{* *}\left(.03^{*}\right)$ & 4.14 \\
\hline \multicolumn{6}{|l|}{ Step 3} \\
\hline Interpersonal skill & .17 & .05 & $3.38^{* *}$ & & \\
\hline Citizenship frequency & .75 & .31 & $2.42^{*}$ & & \\
\hline Citizenship frequency (quadratic) & -.70 & .29 & $-2.41^{*}$ & & \\
\hline Interpersonal skill X Citizenship frequency & .28 & .46 & 0.59 & & \\
\hline Interpersonal skill X Citizenship frequency (quadratic) & -.58 & .26 & $-2.24^{*}$ & $.16^{* *}\left(.03^{*}\right)$ & 2.55 \\
\hline $\begin{array}{l}\text { Inflection points }\left(-B_{1} /{ }^{*} B_{2}\right) \text { by levels of interpersonal sh } \\
\quad+1 S D \text { inflection point }=.62 \\
-1 S D \text { inflection }\end{array}$ & & & & & \\
\hline
\end{tabular}

Note. $N=366$. Dependent variable is task performance; inflection points are on the standardized scale of citizenship frequency. $S E=$ standard error; $S D=$ standard deviation.

${ }^{*} p<.05 .{ }^{* *} p<.01$.

For example, socially dense conditions appear to delay the inflection to nearly double the frequency of citizenship (i.e., from .5 to $1 S D$ above the mean), and in contexts of high autonomy the inflection is postponed almost three times (i.e., from 0.56 to $1.6 \mathrm{SD}$ above the mean). The moderating impacts of high interdependence and low accountability, although significant, appear to be relatively less potent. With regard to individual differences, though the buffering effect of high interpersonal skill is also relatively weaker, individuals with low interpersonal skill reach the inflection point particularly early (i.e., .33 SD above the mean). Rapp et al. (2013) also found diminishing returns when citizenship levels were high, but only among poor time managers.

\section{Study Limitations}

The findings presented here should be considered with respect to study limitations. First, our design was cross-sectional, which precludes our ability to make causal inferences. Second, the measure of task performance included in this study was a subjective

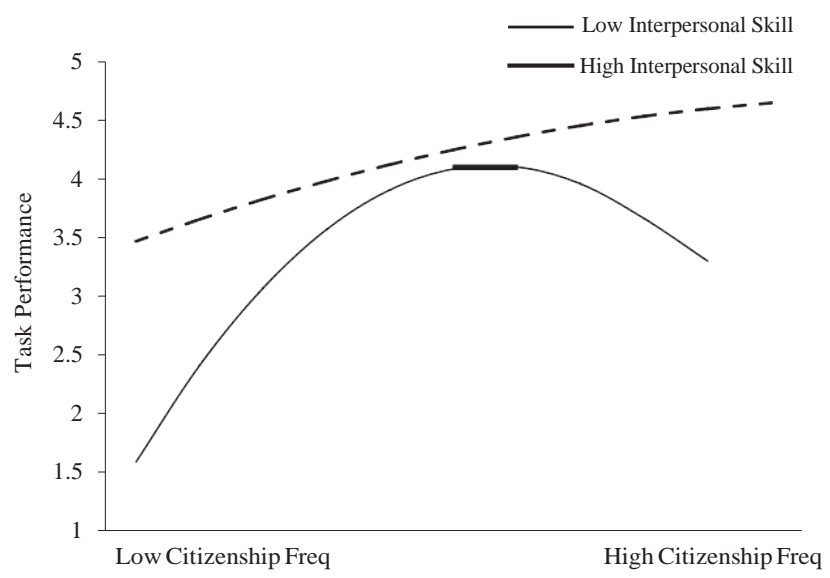

Figure 4. Moderating effects of interpersonal skill. Freq = frequency. managerial evaluation; different conclusions might have been reached if other types of task performance measures had been used. However, Rapp et al. (2013) found a curvilinear association between citizenship frequency and objective measures of performance in a sales context, providing evidence that this relationship generalizes across different measures. Third, we focused exclusively on the "frequency" of citizenship behavior, as this was consistent with resource-allocation-based hypotheses. Such an approach does not capture the level of "effectiveness" in performing citizenship behaviors. As others have noted (Hanson \& Borman, 2006), it is possible that "one worker might spend a lot of time helping coworkers but do so ineffectively whereas another worker spends less time but is actually more helpful” (p. 161). Future research is needed to better understand the nature of the relationship between both the frequency and the effectiveness of citizenship and task performance. Fifth, citizenship frequency was selfreported. Although consistent with how behavioral frequency is typically measured in the work analysis literature, this is inconsistent with how organizational citizenship behaviors such as interpersonal helping are typically measured; thus, our findings might have differed if we had obtained ratings of citizenship frequency from peers or supervisors. Sixth, the observed zero-order correlation between citizenship and task performance in our study could be characterized as relatively modest $(r=.18)$ compared with the magnitude of correlations in other citizenship studies (Podsakoff et al., 2009). However, the size of the correlation in our study is similar to those in Rapp et al. ( $r=.24$ and .25) and Rubin et al. $(r=.16)$, and recent scholarship points to a substantial overestimation of the citizenship-task performance relationship present across much of the literature (Podsakoff, Whiting, Welsh, \& Mai, 2013).

\section{Implications for Future Research and Practice}

Our overall findings suggest that further examination of the context and consequences of citizenship behavior is justified. The trade-off that occurs between citizenship and task performance 
Table 7

Moderation Results From Supplemental Analysis

\begin{tabular}{lrrrrr}
\hline \multicolumn{1}{c}{ Moderator } & \multicolumn{1}{c}{ SE } & \multicolumn{1}{c}{$R^{2}$} & $F$ \\
\hline Social density X Citizenship frequency & -1.59 & .45 & $-3.52^{* *}$ & & \\
Social density X Citizenship frequency (quadratic) & 1.53 & .42 & $3.59^{* *}$ & $.18^{* *}$ & 5.54 \\
Social support X Citizenship frequency & -0.12 & .22 & -0.53 & & \\
Social support X Citizenship frequency (quadratic) & 0.17 & .22 & 0.80 & $.17^{* *}$ & 5.14 \\
Interdependence X Citizenship frequency & 0.45 & .21 & $2.14^{*}$ & & \\
Interdependence X Citizenship frequency (quadratic) & -0.12 & .23 & -0.52 & $.26^{* *}$ & 8.89 \\
Interpersonal skill X Citizenship frequency & 0.59 & .45 & 1.29 & & \\
Interpersonal skill X Citizenship frequency (quadratic) & -0.66 & .30 & $-2.19^{* *}$ & $.26^{* *}$ & 8.89 \\
\hline
\end{tabular}

Note. Models included main and interaction effects of control variables examined in previous studies of curvilinear effects of citizenship (accountability, autonomy, time management). $F$ values are for the full models. $S E=$ standard error.

${ }^{*} p<.05 .^{* *} p<.01$.

points to the need for research examining the mechanisms of this effect. Employees significantly vary in the extent that citizenship is construed as an important aspect of overall performance (McAllister, Kamdar, Morrison, \& Turban, 2007), and this construal process predicts whether or not they ultimately engage in citizenship (Dierdorff et al., 2012). For instance, meta-analytic evidence indicates that when employees feel that they have contradictory expectations (i.e., role conflict), citizenship behavior is negatively affected (Eatough, Chang, Miloslavic, \& Johnson, 2011). Thus, the way employees perceive citizenship in relation to other role demands could influence resource allocation trade-offs. Future research might examine how role perceptions, such as role conflict, role overload, or citizenship challenge or hindrance (Gilboa, Shirom, Fried, \& Cooper, 2008), shape the diminishing returns we find in this study.

With respect to practical implications, our findings suggest that social density decelerates the onset of curvilinearity. As such, interventions designed to increase helping behavior must recognize that such behavior is predicated on the assumption that others exist within close proximity to help. Employees who primarily telecommute may find that their opportunities for citizenship are limited, and, although they may devote fewer resources to citizenship, they may correspondingly establish fewer reciprocal exchanges that benefit their own task performance. With regard to interdependence, organizations that structure workforces into highly interdependent work teams can also expect a more enduring positive effect of citizenship on task performance. Although our results suggest a task performance benefit at lower levels of citizenship, in work settings with low interdependence and social density, employees should be wary of devoting excessive resources to these helping behaviors. In such situations, the point of potential "costs" for employees may arrive even at moderate frequencies of citizenship.

Finally, those who are more proficient in their social interactions are able to maintain the positive association between helping and task performance longer before reaching the point of diminishing returns. Coupled with other evidence regarding benefits of interpersonal skill (e.g., Gaugler et al., 1987; Ng et al., 2005), our results suggest that organizations may consider selecting employees with greater skill. Such employees can perhaps be more efficient in their allocation of resources toward interpersonal helping and thus maintain task performance benefits even at higher levels of frequency. Given the trainability of interpersonal skill, there may be benefits of improving relationship building or communication so as to buffer the diminishing returns of frequently engaging in citizenship.

Our study contributes data to the burgeoning empirical evidence that depicts the intricacy of the citizenship-task performance relationship. We provide corroborative evidence of the trade-off involved when employees dedicate too many personal resources toward citizenship in the performance of their work roles. We find that contextual features and personal attributes that are social in nature decelerate the diminishing returns of citizenship on task performance. Such results are consistent with the notion of citizenship behaviors as social contributions to work performance, which help to form the foundation for reciprocal social exchanges. Given the central role citizenship plays in individual, group, and organizational effectiveness, a deeper understanding of the mechanisms of curvilinearity we observe, as well as other factors that might decelerate these the diminishing returns, seems particularly pressing for future scholarship.

\section{References}

Arthur, W., Jr., Day, E. A., McNelly, T. L., \& Edens, P. S. (2003). A meta-analysis of the criterion-related validity of assessment center dimensions. Personnel Psychology, 56, 125-153. doi:10.1111/j.1744-6570 .2003.tb00146.x

Bachrach, D. G., Powell, B. C., Bendoly, E., \& Richey, R. G. (2006). Organizational citizenship behavior and performance evaluations: Exploring the impact of task interdependence. Journal of Applied Psychology, 91, 193-201. doi:10.1037/0021-9010.91.1.193

Bachrach, D. G., Wang, H., Bendoly, E., \& Zhang, S. (2007). Importance of organizational citizenship behaviour for overall performance evaluation: Comparing the role of task interdependence in China and the USA. Management and Organization Review, 3, 255-276. doi:10.1111/j.17408784.2007.00071.x

Becker, G. S. (1965). A theory of the allocation of time. Economic Journal, 75, 493-517. doi:10.2307/2228949

Bergeron, D. M. (2007). The potential paradox of organizational citizenship behavior: Good citizens at what cost? Academy of Management Review, 32, 1078-1095. doi:10.5465/AMR.2007.26585791

Bergeron, D. M., Shipp, A. J., Rosen, B., \& Furst, S. A. (2013). Organizational citizenship behavior and career outcomes: The cost of being a good citizen. Journal of Management, 39, 958-984. doi:10.1177/ 0149206311407508 
Bernardin, H. J., \& Buckley, R. B. (1981). Strategies in rater training. Academy of Management Review, 6, 205-212.

Blau, P. M. (1964). Exchange and power in social life. New York, NY: Wiley.

Bolino, M. C., \& Turnley, W. H. (2005). The personal costs of citizenship behavior: The relationship between individual initiative and role overload, job stress, and work-family conflict. Journal of Applied Psychology, 90, 740-748. doi:10.1037/0021-9010.90.4.740

Bolino, M. C., Turnley, W. H., Gilstrap, J. B., \& Suazo, M. M. (2010). Citizenship under pressure: What's a "good soldier" to do? Journal of Organizational Behavior, 31, 835-855. doi:10.1002/job.635

Bolino, M. C., Turnley, W. H., \& Niehoff, B. P. (2004). The other side of the story: Reexamining prevailing assumptions about organizational citizenship behavior. Human Resource Management Review, 14, 229246. doi:10.1016/j.hrmr.2004.05.004

Bommer, W. H., \& Bartels, L. K. (1996). The Iliad Assessment Center. Bloomington, IN: Tichenor.

Brief, A. P., \& Motowidlo, S. J. (1986). Prosocial organizational behaviors. Academy of Management Review, 11, 710-725. doi:10.5465/AMR.1986 .4283909

Deckop, J. R., Cirke, C. C., \& Andersson, L. M. (2003). Doing unto others: The reciprocity of helping behavior in organizations. Journal of Business Ethics, 47, 101-113. doi:10.1023/A:1026060419167

Dierdorff, E. C., \& Morgeson, F. P. (2007). Consensus in work role requirements: The influence of discrete occupational context on role expectations. Journal of Applied Psychology, 92, 1228 -1241. doi: 10.1037/0021-9010.92.5.1228

Dierdorff, E. C., Rubin, R. S., \& Bachrach, D. G. (2012). Role expectations as antecedents of citizenship and the moderating effects of work context. Journal of Management, 38, 573-598. doi:10.1177/0149206309359199

Dierdorff, E. C., Rubin, R. S., \& Morgeson, F. P. (2009). The milieu of managerial work: An integrative framework linking work context to role requirements. Journal of Applied Psychology, 94, 972-988. doi:10.1037/ a0015456

Eatough, E. M., Chang, C.-H., Miloslavic, S. A., \& Johnson, R. E. (2011). Relationships of role stressors with organizational citizenship behavior: A meta-analysis. Journal of Applied Psychology, 96, 619-632. doi: 10.1037/a0021887

Ferris, G. R., Witt, L. A., \& Hochwarter, W. A. (2001). Interaction of social skill and general mental ability on job performance and salary. Journal of Applied Psychology, 86, 1075-1082. doi:10.1037/0021-9010 .86.6.1075

Fried, Y., Slowik, L. H., Ben-David, H. A., \& Tiegs, R. B. (2001). Exploring the relationship between workspace density and employee attitudinal reactions: An integrative model. Journal of Occupational and Organizational Psychology, 74, 359-372. doi:10.1348/096317901167406

Gaugler, B. B., Rosenthal, D. B., Thornton, G. C., \& Bentson, C. (1987). Meta-analysis of assessment center validity. Journal of Applied Psychology, 72, 493-511. doi:10.1037/0021-9010.72.3.493

Gilboa, S., Shirom, A., Fried, Y., \& Cooper, C. (2008). A meta-analysis of work demand stressors and job performance: Examining main and moderating effects. Personnel Psychology, 61, 227-271. doi:10.1111/j .1744-6570.2008.00113.x

Grant, A. M., \& Mayer, D. M. (2009). Good soldiers and good actors: Prosocial and impression management motives as interactive predictors of affiliative citizenship behaviors. Journal of Applied Psychology, 94, 900-912. doi:10.1037/a0013770

Halbesleben, J. R. B., Harvey, J., \& Bolino, M. C. (2009). Too engaged? A conservation of resources view of the relationship between work engagement and work interference with family. Journal of Applied Psychology, 94, 1452-1465. doi:10.1037/a0017595

Hanson, M. A., \& Borman, W. C. (2006). Citizenship performance: An integrative review and motivational analysis. In W. Bennett, Jr., C. E. Lance, \& D. J. Woehr (Eds.), Performance measurement: Current perspectives and future challenges (pp. 141-173). Mahwah, NJ: Erlbaum.

Hattrup, K., \& Jackson, S. (1996). Learning about individual differences by taking situations seriously. In K. R. Murphy (Ed.), Individual differences and behavior in organizations (pp. 507-547). San Francisco, CA: Jossey-Bass.

Hayduk, L. A. (1983). Personal space: Where we now stand. Psychological Bulletin, 94, 293-335. doi:10.1037/0033-2909.94.2.293

Hoffman, B. J., Blair, C. A., Meriac, J. P., \& Woehr, D. J. (2007). Expanding the criterion domain? A quantitative review of the OCB literature. Journal of Applied Psychology, 92, 555-566. doi:10.1037/ 0021-9010.92.2.555

Hoover, J. D., Giamhatista, R. C., Sorenson, R. L., \& Bommer, W. H. (2010). Assessing the effectiveness of whole person learning pedagogy in skill acquisition. Academy of Management Learning \& Education, 9, 192-203. doi:10.5465/AMLE.2010.51428543

Humphrey, S. E., Nahrgang, J. D., \& Morgeson, F. P. (2007). Integrating motivational, social, and contextual work design features: A metaanalytic summary and theoretical extension of the work design literature. Journal of Applied Psychology, 92, 1332-1356. doi:10.1037/0021-9010 92.5.1332

Johns, G. (2006). The essential impact of context on organizational behavior. Academy of Management Review, 31, 386-408. doi:10.5465/AMR .2006.20208687

Kahneman, D. (1973). Attention and effort. Englewood Cliffs, NJ: Prentice Hall.

Katz, D., \& Kahn, R. (1978). The social psychology of organizations (2nd ed.). New York, NY: Wiley.

Katz-Navon, T. Y., \& Erez, M. (2005). When collective- and self-efficacy affect team performance: The role of task interdependence. Small Group Research, 36, 437-465. doi:10.1177/1046496405275233

Kiggundu, M. N. (1981). Task interdependence and the theory of job design. Academy of Management Review, 6, 499 -508. doi:10.5465/ AMR.1981.4285795

Klein, C., DeRouin, R. E., \& Salas, E. (2006). Uncovering workplace interpersonal skills: A review, framework, and research agenda. In G. P. Hodgkinson \& J. K. Ford (Eds.), International review of industrial and organizational psychology (Vol. 21, pp. $79-126)$. New York, NY: Wiley.

Kozlowski, S. W. J., Gully, S. M., Nason, E. R., \& Smith, E. M. (1999). Developing adaptive teams: A theory of compilation and performance across levels and time. In D. R. Ilgen \& E. D. Pulakos (Eds.), The changing nature of performance: Implications for staffing, motivation, and development (pp. 240-292). San Francisco, CA: Jossey-Bass.

Le, H., Oh, I.-S., Robbins, S. B., Ilies, R., Holland, E., \& Westrick, P. (2011). Too much of a good thing: Curvilinear relationships between personality traits and job performance. Journal of Applied Psychology, 96, 113-133. doi:10.1037/a0021016

Lievens, F. (1998). Factors which improve the construct validity of assessment centers: A review. International Journal of Selection and Assessment, 6, 141-152. doi:10.1111/1468-2389.00085

Lievens, F., \& Sackett, P. R. (2012). The validity of interpersonal skills assessment via situational judgment tests for predicting academic success and job performance. Journal of Applied Psychology, 97, 460-468. doi:10.1037/a0025741

McAllister, D. J., Kamdar, D., Morrison, E. W., \& Turban, D. B. (2007). Disentangling role perceptions: How perceived role breadth, discretion, instrumentality, and efficacy relate to helping and taking charge. Journal of Applied Psychology, 92, 1200-1211. doi:10.1037/0021-9010.92.5 .1200

McIntyre, R. M., \& Salas, E. (1995). Measuring and managing for team performance: Lessons from complex environments. In R. Guzzo \& E. Salas (Eds.), Team effectiveness and decision-making in organizations (pp. 9-45). San Francisco, CA: Jossey-Bass. 
Moorman, R. H., \& Blakely, G. L. (1995). Individualism-collectivism as an individual difference predictor of organizational citizenship behavior. Journal of Organizational Behavior, 16, 127-142. doi:10.1002/job .4030160204

Morgeson, F. P., \& Dierdorff, E. C. (2010). Work analysis: From technique to theory. In S. Zedeck (Ed.), APA handbook of industrial and organizational psychology (Vol. 2, pp. 3-41). Washington, DC: American Psychological Association.

Morgeson, F. P., \& Humphrey, S. E. (2006). The Work Design Questionnaire (WDQ): Developing and validating a comprehensive measure for assessing job design and the nature of work. Journal of Applied Psychology, 91, 1321-1339. doi:10.1037/0021-9010.91.6.1321

Morgeson, F. P., Reider, M. H., \& Campion, M. A. (2005). Selecting individuals in team settings: The importance of social skills, personality characteristics, and teamwork knowledge. Personnel Psychology, 58, 583-611. doi:10.1111/j.1744-6570.2005.655.x

Mowday, R. T., \& Sutton, R. I. (1993). Organizational behavior: Linking individuals and groups to organizational contexts. Annual Review of Psychology, 44, 195-229. doi:10.1146/annurev.ps.44.020193.001211

Ng, T. W. H., Eby, L. T., Sorensen, K. L., \& Feldman, D. C. (2005). Predictors of objective and subjective career success: A meta-analysis. Personnel Psychology, 58, 367-408. doi:10.1111/j.1744-6570.2005 .00515.x

Nielsen, T. M., Bachrach, D. G., Sundstrom, E., \& Halfhill, T. R. (2012). Utility of OCB: Organizational citizenship behavior and group performance in a resource allocation framework. Journal of Management, 38, 668-694. doi:10.1177/0149206309356326

Oldham, G. R., \& Fried, Y. (1987). Employee reactions to workspace characteristics. Journal of Applied Psychology, 72, 75-80. doi:10.1037/ 0021-9010.72.1.75

Organ, D. W., Podsakoff, P. M., \& MacKenzie, S. B. (2006). Organizational citizenship behavior: Its nature, antecedents, and consequences. Thousand Oaks, CA: Sage.

Ozer, M. (2011). A moderated mediation model of the relationship between organizational citizenship behaviors and job performance. Journal of Applied Psychology, 96, 1328-1336. doi:10.1037/a0023644

Paulus, P. B. (1980). Crowding. In P. Paulus (Ed.), Psychology of group influence (pp. 245-289). Hillsdale, NJ: Erlbaum.

Podsakoff, N. P., Whiting, S. W., Podsakoff, P. M., \& Blume, B. D. (2009). Individual- and organizational-level consequences of organizational citizenship behaviors: A meta-analysis. Journal of Applied Psychology, 94, 122-141. doi:10.1037/a0013079

Podsakoff, N. P., Whiting, S. W., Welsh, D. T., \& Mai, K. M. (2013). Surveying for "artifacts": The susceptibility of the OCB-performance evaluation relationship to common rater, item, and measurement context effects. Journal of Applied Psychology, 98, 863- 874. doi:10.1037/ a0032588

Podsakoff, P. M., MacKenzie, S. B., Paine, J. B., \& Bachrach, D. G. (2000). Organizational citizenship behaviors: A critical review of the theoretical and empirical literature and suggestions for future research. Journal of Management, 26, 513-563. doi:10.1177/014920630002600307

Rapp, A. A., Bachrach, D. G., \& Rapp, T. L. (2013). The influence of time management skill on the curvilinear relationship between organizational citizenship behavior and task performance. Journal of Applied Psychology, 98, 668-677. doi:10.1037/a0031733

Reilly, R. R., Henry, S., \& Smither, J. W. (1990). An examination of the effects of using behavior checklists on the construct validity of assessment center dimensions. Personnel Psychology, 43, 71-84. doi:10.1111/ j.1744-6570.1990.tb02006.x

Riggio, R. E. (1986). Assessment of basic social skills. Journal of Personality and Social Psychology, 51, 649-660. doi:10.1037/0022-3514 51.3.649

Rode, J. C., Arthaud-Day, M. L., Mooney, C. H., Near, J. P., Baldwin, T. T., Bommer, W. H., \& Rubin, R. S. (2005). Life satisfaction and student performance. Academy of Management Learning \& Education, 4, 421-433. doi:10.5465/AMLE.2005.19086784

Rubin, R. S., Dierdorff, E. C., \& Bachrach, D. G. (2013). Boundaries of citizenship behavior: Curvilinearity and context in the citizenship and task performance relationship. Personnel Psychology, 66, 377- 406 doi:10.1111/peps.12018

Sackett, P. R., \& Wilson, M. A. (1982). Factors affecting the consensus judgment process in managerial assessment centers. Journal of Applied Psychology, 67, 10-17. doi:10.1037/0021-9010.67.1.10

Szilagyi, A. D., \& Holland, W. E. (1980). Changes in social density: Relationships with functional interaction and perceptions of job characteristics, role stress, and work satisfaction. Journal of Applied Psychology, 65, 28-33. doi:10.1037/0021-9010.65.1.28

Thornton, G. C., III, \& Mueller-Hanson, R. A. (2004). Developing organizational simulations: A guide for practitioners and students. Mahwah, NJ: Erlbaum.

Van Scotter, J. R., Motowidlo, S. J., \& Cross, T. C. (2000). Effects of task performance and contextual performance on systemic rewards. Journal of Applied Psychology, 85, 526-535. doi:10.1037/0021-9010.85.4.526

Vigoda-Gadot, E. (2006). Compulsory citizenship behavior: Theorizing some dark sides of the good soldier syndrome in organizations. Journal for the Theory of Social Behaviour, 36, 77-93. doi:10.1111/j.1468-5914 .2006.00297.x

Viswesvaran, C., \& Ones, D. S. (2000). Perspectives on models of job performance. International Journal of Selection and Assessment, 8, 216-226. doi:10.1111/1468-2389.00151

Weisberg, S. (2005). Applied linear regression (3rd ed.). Hoboken, NJ: Wiley/Interscience. 